\title{
Cultural Security and Innovative Development in the Context of Globalization of Chinese National Sports
}

\author{
Wei Yu \\ School of Physical Education of Sichuan Agricultural University, Ya'an, Sichuan, China
}

Keywords: Chinese national sports; globalization; cultural security; innovation and development.

\begin{abstract}
The traditional sports culture of China is facing challenges in the context of globalization. With the changes of modern lifestyles, as well as the influence of Western sports culture, the safety and development of Chinese national sports culture are facing great challenges. China's traditional national sports culture is composed of various ethnic minority sports culture, which is formed by constantly separation and integration. The traditional sports culture promote the idea of "harmony and different", although they have identity and adaptation to the culture, they still have their own characteristics. For the introduction of Western sports culture, there will be an exclusion, identity, inclusive attitude. National sports culture is facing the survival crisis, mainly because of the lack of cultural innovation, some people have skeptical attitude on Chinese national sports culture, and the traditional sports culture has small market development space. So only to keep pace with the times, reform and innovation, can the Chinese national cultural heritage continue to develop. Therefore, only the constant advance with the times, reform and innovation can allow the Chinese national cultural heritage to develop continually.
\end{abstract}

\section{Introduction}

Cultural security is as important as national political and economic security, which is the performance of a country's comprehensive national strength and is an important part of the national security system. In recent times, globalization has become a trend, the cultures all over the word exchange, collide and integrate mutually. Culture and economic exchanges, cultural and political exchanges have continued to deepen. All of these represent the comprehensive national strength, and national culture represents the national spirit, which is an essential part of the survival and development of a nation. With the continuous penetration of Western culture, our country's cultural security is facing a crisis. How to make the Chinese national sports develop safely in the context of globalization has become an important research issue, which also is one of the tasks of developing socialism with Chinese characteristics.

\section{The Security Of National Sports Culture Faces Challenges In The Globalization.}

Many Chinese and foreign scholars believe that globalization has been unstoppable, English has become the world's common language, and mass media culture has become popular. The so-called globalization, that is, cultural consistency, in this process, a lot of different cultures gradually converge, become more and more similar, and in the continuous development, different cultural characteristics in each nation and each region will disappear. This has brought great challenges to the development of various national cultures. There are many aspects to threat the safety of national sports culture, not only the infiltration of Western culture, but also the influence of some internal factors. The Olympic Games is the infiltration of Western sports culture, this strong culture seriously affected the development of national traditional culture. But the decisive factor is the internal threat, that is, the spiritual power that support this nation. [1]

Lack of cultural innovation. In order to inherit the development of a national sports culture, the immutable is impossible, it must continue to follow the trend of the times, and carry out innovation 
and development. The innovation of national sports culture will also affect the safety of sports culture. It not only survival and develop in the entire nation, but also survival and develop in the world. So it is necessary to carry out cultural innovation, it is the only way to adapt to the development of the times and the requirements of globalization. However, in the history of inheritance and development, most of our traditional Chinese sports cultures are immutable, and they have a little innovation. This is also the reason why the traditional Chinese sports culture gradually dies. But through continuous development, our Chinese national sports culture leaves a lot of valuable resources, we should inherit these excellent traditional culture, and it will be collated and flourished. We not only to inherit it, but also to make it face the world, face the future, to make the nation's become the world's. So that the Chinese people to increase the identity of traditional sports culture, and to enhance national cohesion. In the face of foreign sports culture invasion, the Chinese culture should absorb the valuable part of foreign culture for itself, and on this basis, it should carry out continuous innovation, to face the world with the open attitude. Only in this way, the traditional Chinese sports culture will not be abandoned by the times and continue to develop. The traditional culture of the Chinese nation can be protected. [2]

Lack of consciousness of national sports culture. The so-called cultural security issues, is in which attitude to face different cultures' confrontation with each other. It should has a basic attitude towards the question of cultural security, that is, cultural consciousness. The so-called cultural consciousness is a person's understanding to the culture, whether understand the development history of the culture, the formation process and the future development trend, compared to other cultures, where are the differences. In this process, for the cultural intersection which we can not stop - the penetration of Western culture, we should have a correct attitude, can not be fully accepted and can not be completely negative. Borrowing a sentence that is "Every form of beauty has its uniqueness, precious is to appreciate other forms of beauty with openness, if beauty represents itself with diversity and integrity, the world will be blessed with harmony and unity", which means that each culture has its own characteristics, has its own advantages, it is necessary to absorb the advantages of different cultures and carry out innovation in the basis of its own culture development, so as to form the scene of culture prosperity. Western sports culture advocates the concept of competition and surpassing, it believes that only in the constant competition, it can surpass the opponent and surpass itself. The traditional sports culture of the Chinese nation advocates entertainment, physical fitness, cultivating mood, and it pays less attention to athletics, although in recent years, a few people are gradually aware of this problem, but most people still lack the cultural consciousness. [4]

There are doubts and criticism about the national sports culture. What is cultural identity, cultural identity is formed in the same belief, the same language, the same world view, values and moral values. In other words, if a country want to have the national cohesion, it is necessary to have the common interest and common moral values with the people. The so-called crisis faced by national sports culture, that is, some people are influenced by the foreign sports culture and gradually recognize the foreign culture, they generate doubts and criticize the national culture, fully accept the foreign culture. So that the foreign sports culture will gradually replace the traditional Chinese sports culture. So people need to find cultural identity, especially our country has five thousand years of cultural development history and there are 56 nationalities. In this context, the formation of the sports culture will naturally be affected by the impact of globalization, many people will ask who we are? And they will question their own national culture. [5]

\section{How To Innovate And Develop.}

Bring forth the new through the old. In the process of development, our country's national sports culture should be innovative. Innovation is the source of development, if we want to make our country's national sports culture can be passed down, able to board the world stage, and integrate with the world mainstream sports culture, it is necessary to carry out culture innovation. Only to enhance the innovation of national culture, it is possible to change the contrast difference of the world's sports cultural forces. In the face of people's doubts to national sports culture, the national sports culture must change this situation, that is, to carry out sports culture innovation. We should carry out 
innovation and reform on the content of sports culture, various forms, as well as the system, so as to change the people's concept to sports culture to create an atmosphere of innovation, so that our country's sports culture will be able to retain the essence of their own culture and constantly absorb the essence parts of different national cultures, with the development of the times and the infiltration of foreign culture.

Harmony but not uniformity. Although the Olympic movement respects facing the world, not inclining to any region or country, regardless of Europe or Western countries. But in the actual implementation process, we can realize that the Olympic movement is more inclined to the values of the West, the Olympic movement respects the concept of "faster, higher, stronger". In the continuous competition, it respects surpassing oneself and surpassing the nature, and it does not attach importance to the development of national sports in each country. In this development process, it even suppress the progress of some countries' national sports culture in a certain extent. These are affecting the development and progress of our national sports culture. In the infiltration process of Western sports culture, our national sports culture should hold an open and developed attitude to absorb the essence of Western sports culture and learn some useful things to inject the fresh blood into our national sports culture and add vitality. We can not be biased, or make the overall reception and the overall negative. We should hold an objective attitude to look at it. Also, we should recognize the cultural differences to maintain the characteristics of the national culture and exist with different cultures in harmony to promote common development and progress. [3]

Advancing with the times. Our national sports culture has five thousand years' cultural heritage, have its own independent value orientation, ideal pursuit, national characteristics, and continue to inherit and develop. But with the progress of the times, people's values change, they have a new concept of awareness to the sports. National sports culture should be based on the public, based on the people. It should face the society, the world and the future. It should absorb the useful part of the different national cultures and use for itself. Also, it should carry out continuous practice, improvement and development, advancing with the times to build a national sports culture.

Self-improvement. There are a lot of people do not pay much attention to the national sports cultural undertakings, they think that it is the responsibility of our country. It's everyone's responsible to inherit our country's outstanding sports culture, everyone must vigorously carry forward the Chinese national excellent sports culture. This requires to carry out sports culture education for each generation new forces. Because the younger generation accept the new things more widely and they have strong ability to accept. But the different national sports cultures of the world flow together and collide, which makes many young people have doubts to the national sports culture's identity. This is due to the young generation is not enough understanding the national sports culture and their understanding is also relatively shallow. So it is necessary for these people to carry out sports culture education. We should regard the college students and high school students as the main education objects, we can set up some martial arts classes or allow students to practice tai chi in the intercourse to make the traditional Chinese martial arts into the classroom, so that to deepen the students the cognition to the Chinese traditional sports, it is necessary, only in this way, the traditional Chinese sports culture can be inherited and carried forward, also it can make the students have a sense of identity to the Chinese traditional sports culture.

Change passive into initiative. Use this powerful time that our country holding the Olympic Games to seize the opportunity. In this process, the government should increase the investment of funds, with the help of all sectors of the community to raise funds to develop national sports industry. Also, the government should respect the economic laws of the market, vigorously promote some minority sports culture and use of tourism development to promote the traditional sports culture, so that people can accept the traditional sports culture subtly in the process of visiting tourism to form the traditional sports tourism. This will be able add strength for our country's traditional sports and cultural development from the internal. 


\section{Conclusion}

While constantly absorbing the excellent part of foreign sports culture, the Chinese traditional sports culture should also be innovative. Combined with the characteristics of the development of the times, it should carry forward the characteristics of the traditional Chinese sports culture. In this process, the traditional sports culture must strictly regulate the system, as well as regulate the management of material culture. Through the school, we can carry out some martial arts courses and tai chi practice to enhance the students cultural identity to the traditional culture. Of course, different areas have different cultural identity, with time and space differences. The traditional sports culture of the nation will change with the development of the times. Each era has different characteristics of the times, the national sports culture in different times have different characteristics. In order to reduce the different national culture assimilation, there is the phenomenon that they lost their own national culture characteristics. Whether the internal influence or the external influence, in the face of different cultural infiltration, the Chinese national sports culture has a process of adaptation, repulsion, acceptance and containment, the emergence showed in this process is the identity to the culture.

\section{Acknowledgement}

Project:1. Humanities and Social Sciences Federation Youth progject of Sichuan Agricultural University: construction of rural community sports service system in new rural construction-taking Sichuan province as example (No.XCK201222); 2.self-raised project in sichuan province department of education: research of construction of Tai chi culture promotion platform in colleges and universities of Sichuan province (No.: 12SB296).

\section{References}

[1] Wang Daili. Dicussion on Globalization and National Cultural Identity [J]. Journal of the Party School of Guizhou Provincial Committee of the C.P.C, 2007, 22(6): 33-36.

[2] Zhang Yue, Shu Lili. Cultural Consciousness and Cultural Identity: Changes in the Relationship between Ethnic and Religious Cultures in Bingzhongluo Area of Nujiang Canyon [J]. Study of the Ethnic Groups in the Southwest Frontier, 2007, (5): 69-87.

[3] Wan Minggang. Human Behavior in Cultural Perspective [M]. Lan Zhou: Gansu Culture Press, 1996:233.

[4] Lin Xingzhi. Sports Globalization - Harmonious Coexistence between World Sports Culture and National Sports Culture [J] Journal of Shandong Normal University: Humanities and Social Sciences, 2006, 61, (4):104-107.

[5] Lou Zhangsheng, Yuan Xiaowei, Wang Zhenjie etc. 2008, 12,(15): 87. Inheritance Crisis of National Sports Culture from the Perspective of Sports Globalization [J]. Journal of Physical Education, 2008, 12, (15): 87. 